\title{
Milk Fatty Acids II: Prediction of the Production of Individual Fatty Acids in Bovine Milk
}

\author{
P. J. Moate, ${ }^{\star} \dagger^{1}$ W. Chalupa, ${ }^{\star}$ R. C. Boston, ${ }^{*}$ and I. J. Lean $\dagger$ \\ *University of Pennsylvania, Kennett Square 19348 \\ †School of Veterinary Science, University of Sydney, New South Wales, Australia 2006
}

\begin{abstract}
Previously observed relationships between dietary composition and production of a small number of individual milk fatty acids were the motivation to examine whether equations could be developed to predict production of all the major individual milk fatty acids. Such equations could be incorporated into ration formulation programs and used to examine factors that influence milk fat composition. Data from 29 published experiments on Holstein cows that provided 120 dietary treatments were entered into CPM-Dairy to obtain estimates of amounts of individual long-chain fatty acids (LCFA) absorbed from the intestines. These derived data and other dietary and animal data including the reported fatty acid composition of milk fat were entered into a spreadsheet. Descriptors of diet included daily intake of dry matter, total fermentable carbohydrate, total fatty acids, and profile of dietary fatty acids, intake of neutral detergent fiber, supplemental fish-oil, buffer, and magnesium oxide. Cow data included body weight and days in milk (DIM). Multiple linear regression was used to develop equations to predict the production $(\mathrm{g} / \mathrm{d})$ of each of 26 major LCFA. The equations developed generally had $R^{2}$ values in excess of 0.5 . Production $(\mathrm{g} / \mathrm{d})$ of total de novo fatty acids (C4:0 to C15:0) (PTdenovo) was found to be positively related to the intake of fermentable carbohydrate, and negatively related to the intake of fish oil fatty acids and the estimated total amount of unsaturated fatty acids absorbed from the intestines. The PTdenovo was greater in pasture-fed cows than total mixed ration-fed cows and was negatively related to the square root of DIM. Production of each individual de novo fatty acid was described by a fixed proportion of PTdenovo. These proportions were $0.12 \pm 0.006$ (C4:0), $0.083 \pm 0.0039$ (C6:0), $0.0516 \pm 0.0025$ (C8:0), $0.111 \pm$ $0.003(\mathrm{C} 10: 0), 0.134 \pm 0.0037(\mathrm{C} 12: 0), 0.441 \pm 0.007$ (C14:0), $0.046 \pm 0.0024(\mathrm{C} 14: 1)$, and $0.0432 \pm 0.0017$
\end{abstract}

Received March 23, 2007.

Accepted November 26, 2007.

${ }^{1}$ Corresponding author: moate@vet.upenn.edu
(C15:0). Separate independent equations were developed to describe the daily production of C16:0, C16:1, and the main individual preformed fatty acids $(>\mathrm{C} 16)$. The productions of each of the main individual preformed fatty acids were generally strongly related to the corresponding estimated amount (g/d) of specific fatty acids absorbed from the intestines. Percentage estimates for the direct transfer of the major absorbed LCFA to their corresponding LCFA in milk were $42 \%$ (C16:0); 9.5\% (C18:0); 47.5\% (cis-9 C18:1); 16.1\% (all isomers of trans-C18:1), 38\% (cis-9, cis-12 C18:2); and $31 \%$ (cis-9, cis-12, cis 15 C18:3). High dietary intake of fish oil fatty acids was negatively associated with the production of all of the major individual preformed fatty acids with the exception of $\mathrm{C} 20: 5$ and C22:6. In some instances, particular dietary factors were found to have positive influences on production of one fatty acid and negative influences on another. For example, high levels of dietary magnesium oxide were positively associated with production of $\mathrm{C} 17$ fatty acids but negatively associated with production of C18:0 and cis-9, trans-11 C18:2 (conjugated linoleic acid). This analysis quantified effects of major dietary and cow factors on production of individual fatty acids in milk.

Key words: milk, fatty acid, model, prediction

\section{INTRODUCTION}

A growing awareness of the health and metabolic properties of individual milk fatty acids (McGuire and Bauman, 2002; Parodi, 2002; Bauman and Griinari, 2003) is part of the motivation behind this attempt to model the production of individual milk fatty acids. In 1995, the first systematic attempt was made to produce a static model of changes in milk fatty acid profile in response to dietary fat supplements (Hermansen, 1995). A generalized linear model was used to relate proportions of individual fatty acids in milk fat to their concentrations in the diet. Dietary treatments that involved fish meal or fish oil, calcium salts of fatty acids, and fat supplements chemically protected against ruminal influence were excluded from the analysis. Hermansen (1995) also excluded diets in which dietary 
C18:2 and C18:3 given as free oil exceeded $2.5 \%$ of total $\mathrm{DMI}$ and did not attempt to predict individual proportions of fatty acids with chain length less than 12 carbon atoms, nor differentiate between different isomers of C18:1 and C18:2. However, he did show that for fatty acids with more than 12 carbon atoms, there were generally statistically significant $(P<0.05)$ associations between intake of specific fatty acids and the proportion of the corresponding fatty acid in milk fat. Difficulties in predicting the proportions of $\mathrm{C} 18: 0$ and $\mathrm{C} 18: 1$ were hypothesized to be due to differing extents of ruminal biohydrogenation (BH) of unsaturated fatty acids, and to different abilities of cows to desaturate C18:0 to C18:1 (Hermansen, 1995).

A dynamic model of milk fat synthesis was developed by Hanigan and Baldwin (1994), in which milk fatty acids were described by 3 separate pools: short-chain fatty acids ranging in chain length from 4 to 8 carbons, medium-chain-length fatty acids with between 10 to 16 carbons, and fatty acids with more than 16 carbons. The model did not distinguish between saturated and unsaturated fatty acids (Hanigan and Baldwin, 1994). Recently, Shorten et al. (2004) developed a second dynamic model of long-chain fatty acids (LCFA) in milk fat that, like the earlier model of Hanigan and Baldwin (1994), did not examine all major individual fatty acids. Instead, the milk fat composition was modeled in terms of short-chain fatty acids (C4:0 to C14:0), and 4 individual fatty acids: C16:0, C16:1, C18:0, and C18:1. Shorten et al. (2004) used nonlinear differential equations to provide a dynamic prediction of how concentrations of milk fatty acids change over time with respect to changes in dietary inputs of fatty acids. This elegant model used more than 27 parameters, the values of each being defined by reference to between 1 and 3 published experiments. The model was evaluated by comparing model predictions of proportions of individual milk fatty acids with data from 4 different milks obtained from 1 experiment. The limited data from which the model was derived suggest that further refinement of this model will be likely.

Recently there has been further development and widespread use of CPM-Dairy (http://www.cpmdairy. com), a dairy ration formulation program (Boston et al., 2002). CPM-Dairy is a static model that predicts the steady-state response to a particular dietary treatment. It includes a fat submodel and an extensive feed dictionary describing the fatty acid profile and total fatty acid composition of over 300 feeds (Moate et al., 2004, 2006). The fat submodel in the CPM-Dairy program estimates the extent of ruminal lipolysis and $\mathrm{BH}$ of dietary LCFA as well as amounts of 10 individual LCFA absorbed in the intestines. The capabilities of CPM-Dairy overcome the problems of variable lipolysis and $\mathrm{BH}$ that confounded predictions made by Hermansen (1995). These recent developments facilitate the potential for development of a quantitative model to predict the influence of dietary and cow factors on production of major individual LCFA in milk and of total milk fatty acids. Furthermore, if milk volume is known or can be accurately predicted, the concentrations of individual milk fatty acids and of total milk fatty acids may also be predicted.

In a companion paper (Moate et al., 2007), we have shown that the concentrations of individual fatty acids in milk vary substantially and that they do not all vary in concert. Moate et al. (2007) found that concentrations of almost all of the individual de novo fatty acids were positively correlated $(P<0.05)$ with each other and with the total concentration of de novo fatty acids, but the total concentration of de novo fatty acids was generally negatively correlated $(P<0.05)$ with each of the individual unsaturated preformed fatty acids. Furthermore, within the preformed group of fatty acids, the concentrations of some individual fatty acids were positively correlated with some fatty acids and negatively with others. These findings suggest the necessity of separate equations to predict the production of individual fatty acids. The objectives of this paper were to develop equations to predict the influence that cow and dietary factors have on the daily production of major individual LCFA from C4:0 to C22:6. To achieve these objectives, data from 29 experiments from 28 papers that examined the influence of cow factors and dietary composition on milk fat yield and on the profile of different LCFA in milk fat were collated and analyzed. This paper presents findings related to the prediction of the daily production of the 26 individual major milk fatty acids.

\section{MATERIALS AND METHODS}

\section{Data Collection}

The 28 papers that were the source of data for this analysis are listed in Table 1 of the companion paper (Moate et al., 2007). Details about these papers, especially the criteria for their inclusion in this analysis and the methods and assumptions involved regarding the production data concerning milk fatty acids, have been described previously (Moate et al., 2007).

Production data as well as dietary and cow data from each publication and relevant CPM-Dairy predictions for each diet were entered into an Excel 2003 (Microsoft Corp., Redmond, WA) spreadsheet. The dietary data obtained directly from each publication included DMI, total diet NDF percentage, total diet $\mathrm{CP}$ percentage, total diet fatty acid (FA) percentage, and the fish-oil fatty acids in the total diet (\% of DM). Further, following 
Table 1. Prediction of the production ( $\mathrm{g} / \mathrm{d}$ ) of total de novo fatty acids (PTdenovo; C4:0 to C15:0) and of individual de novo fatty acids

\begin{tabular}{|c|c|c|c|c|c|c|}
\hline $\begin{array}{l}\text { Equation } \\
\text { no. }\end{array}$ & $\begin{array}{l}\text { Dependent } \\
\text { variable }\end{array}$ & $\begin{array}{c}\text { Regression } \\
\text { variable }(\mathrm{s})^{1}\end{array}$ & Coefficient $\pm \mathrm{SE}$ & $\mathrm{t}$ & $\mathrm{N}(\mathrm{n})^{2}$ & $\mathrm{R}^{2}$ \\
\hline \multirow[t]{7}{*}{1} & \multirow[t]{7}{*}{ PTdenovo } & Intercept & $197.1 \pm 42.4$ & 4.65 & \multirow[t]{7}{*}{$120(29)$} & \multirow{7}{*}{0.76} \\
\hline & & IFCHO & $25.8 \pm 4.59$ & 5.62 & & \\
\hline & & ATunsatFA & $-1.05 \pm 0.169$ & -6.20 & & \\
\hline & & ATunsatFA $^{2}$ & $0.0019 \pm 0.0004$ & 5.11 & & \\
\hline & & IfishFA & $-0.259 \pm 0.030$ & -8.57 & & \\
\hline & & Diet & $-22.0 \pm 11.1$ & -1.98 & & \\
\hline & & $\sqrt{D I M}$ & $-6.69 \pm 2.28$ & -2.94 & & \\
\hline 2 & PC4:0 & PTdenovo & $0.122 \pm 0.006$ & 19.1 & $95(23)$ & $\mathrm{NA}^{3}$ \\
\hline 3 & PC6:0 & PTdenovo & $0.083 \pm 0.0039$ & 21.3 & $111(27)$ & NA \\
\hline 4 & PC8:0 & PTdenovo & $0.0516 \pm 0.0025$ & 20.5 & $111(27)$ & NA \\
\hline 5 & PC10:0 & PTdenovo & $0.111 \pm 0.003$ & 42.4 & $111(27)$ & NA \\
\hline 6 & PC12:0 & PTdenovo & $0.134 \pm 0.0037$ & 35.7 & $111(27)$ & NA \\
\hline 7 & PC14:0 & PTdenovo & $0.441 \pm 0.007$ & 65.3 & $111(27)$ & NA \\
\hline 8 & PC14:1c9 & PTdenovo & $0.046 \pm 0.0024$ & 18.9 & $101(24)$ & NA \\
\hline 9 & PC15:0 & PTdenovo & $0.0432 \pm 0.0017$ & 25.5 & $88(21)$ & NA \\
\hline
\end{tabular}

\footnotetext{
${ }^{1}$ ATunsatFA = total amount of unsaturated fatty acids absorbed from the intestines $(\mathrm{g} / \mathrm{d})$; Diet = a categorical variable, 0 = pasture, 1 = TMR; IFCHO = intake of fermentable carbohydrate $(\mathrm{kg} / \mathrm{d})$; IfishFA = intake of fish-oil fatty acids $(\mathrm{g} / \mathrm{d})$.

${ }^{2} \mathrm{~N}=$ number of diets, $\mathrm{n}=$ number of experiments.

${ }^{3} \mathrm{NA}=$ not appropriate.
}

univariate examination of the data, 3 categorical variables were generated to describe attributes of the diet. A dichotomous variable "Diet" was generated with a value 0 to designate a pasture-based diet and 1 to designate a TMR-based diet. A categorical variable designated "Buffer" was used to describe the diets containing supplemental buffers, specifically calcium bicarbonate, sodium bicarbonate, or potassium bicarbonate. The buffer variable was assigned values of 0 to represent diets with no added buffers, values of 1 to represent diets with supplemental buffer greater than 0 but less than $0.2 \%$ of total DMI and values of 2 for diets containing $0.2 \%$ or more of the total DMI as buffer. Another categorical variable "MgO", with category values similar to those of "Buffer", was used to describe supplemental magnesium oxide. The cow data included BW and DIM.

Nutrient data calculated using CPM-Dairy included predicted intake of fermentable carbohydrate (IFCHO, $\mathrm{kg} / \mathrm{d}$ ) in the diet and predicted amounts ( $\mathrm{g} / \mathrm{d}$ ) of individual LCFA absorbed from the intestines (AC12:0, AC14:0, AC16:0, AC16:1, AC18:0, AC18:1t, AC18:1c, AC18:2, AC18:3, and ACother). To obtain these outputs, primary data on the cows and diet were obtained from each publication and entered into the CPM-Dairy ration program. For each diet, the data entered into CPM-Dairy included the amount ( $\mathrm{kg}$ of $\mathrm{DM}$ ) of each major feed, DIM, and the BW of the cows in each experiment. Body weight was not reported in 9 experiments and for 38 diets an assumed BW of $600 \mathrm{~kg}$ was entered into CPM-Dairy. When a particular publication listed a chemical description of individual major feeds in the diet (e.g., CP, NDF, total fatty acids, and fatty acid profiles for forages, grains or fat supplements) these were entered into CPM-Dairy. When chemical descriptions of individual feeds were not given (and this was the majority of cases), then feeds were selected from the CPM-Dairy feed dictionary that were most representative of that type of feed. In all CPM-Dairy sessions, the total dietary concentrations of fatty acids, NDF, and $\mathrm{CP}$ were made to match those reported for that overall diet. This was achieved by adjusting the concentrations of these constituents in the forage component of the diet because it is generally the forage component that is most variable with respect to these constituents. The profile of LCFA in the CPM-Dairy session was made to match the profile of LCFA for the total diet. This was also achieved by adjusting the profile of fatty acids in the forage component of the diet. All estimations using CPM-Dairy were concluded before data analysis commenced. Milk fat yield (MF, g/d) was calculated as:

$$
\mathrm{MF}=\mathrm{MY} \times 10 \times \text { Milk fat } \%,
$$

where MY is milk yield $(\mathrm{kg} / \mathrm{d})$. Production of total milk fatty acids (PTotalFA, g/d) was calculated as:

$$
\text { PTotalFA }=\mathrm{MF} \times 0.933 .
$$

Production of individual fatty acids $(\mathbf{P F A}$, g/d) was calculated as:

$$
\begin{aligned}
\mathrm{PFA}_{\mathrm{i}}= & \mathrm{PTotalFA} \times \mathrm{FA}_{\mathrm{i}} / 100, \\
& \text { Journal of Dairy Science Vol. } 91 \text { No. 3, } 2008
\end{aligned}
$$


where PTotalFA $(\mathrm{g} / \mathrm{d})$ is the total production of milk fatty acids, $\mathrm{FA}_{\mathrm{i}}$ is the percentage of each of the following individual milk fatty acids or groupings of fatty acids in the total milk fatty acids: C4:0, C6:0, C8:0, C10:0, C12:0, C14:0, cis (c)-9 C14:1, C15:0, C16:0, cis-9 C16:1, C17; C18:0, trans (t)-6-8 C18:1, trans-9 C18:1, trans10 C18:1, trans-11 C18:1, trans-12 C18:1, cis-9 C18:1, cis-9, cis-12 C18:2, cis-9, trans-11 C18:2, trans-10, cis12 C18:2, CLAother, C18:3, C20:0, C20:5, C22:6, and Others. The concentration $(\mathrm{g} / \mathrm{kg})$ of individual fatty acids in milk was defined as

$$
\left[\mathrm{Fa}_{\mathrm{i}}\right]=\mathrm{PFa}_{\mathrm{i}} / \mathrm{MY} \text {. }
$$

Fatty acids in bovine milk are considered to be synthesized de novo in the mammary gland or derived from plasma lipids (Taylor and MacGibbon, 2002). Generally C4:0 to C14:0 and some C16:0 is thought to be synthesized de novo in the mammary gland (Grummer, 1991). However, in this investigation, C4:0 to C15:0 will be designated as de novo fatty acids and the production of total de novo fatty acids (PTdenovo, g/d) is defined as the sum of PC4:0 to PC15:0:

$$
\text { PTdenovo }=\sum_{\mathrm{i}=4}^{\mathrm{i}=15} \mathrm{PFa}_{\mathrm{i}}
$$

Milk fatty acids that are not produced de novo in the mammary gland are often termed preformed fatty acids (McGuire and Bauman, 2002). Preformed fatty acids are generally considered as containing some C16 milk fatty acids and milk fatty acids with more than 16 carbon atoms. In this analysis, the term "preformed fatty acids" will be used to signify only fatty acids with more than 16 carbon atoms and the production of preformed fatty acids (PTpreform, g/d) is defined as

$$
\text { PTpreform }=\sum_{i=17}^{i=22} \mathrm{Fa}_{\mathrm{i}}
$$

\section{Statistical Analysis}

Data were initially explored using univariate descriptive analysis and graphing of variables. Data were examined for outliers and nonlinearity of response. Multiple linear regression was used to examine major dietary and animal factors that influence the yield of total and individual milk fatty acids. Data were weighted by the number of cows in each treatment. Regressions were clustered on experiment to take into account the possibility that treatments within experiments may not be independent with respect to measurement and analytical errors.
The choice of variables for each regression was influenced by a number of factors. In all cases, the independent variables used in each regression were chosen on the basis of relevance to the particular regression, in that these had either been previously reported to influence that particular dependent variable or to at least have an influence on milk fat percentage. An important consideration was that the authors intend to incorporate these equations into the CPM-Dairy fat submodel to provide a tool to predict milk fatty acid composition. Therefore, only parameters that can currently be extracted from CPM-Dairy, or easily incorporated into CPM-Dairy, were included in regression equations. The independent variables used in these analyses included: BW, DIM, DMI, Diet, MgO, Buffer, IFCHO, intake of total fatty acids (ITotalFA), intake of NDF (INDF), intake of fish-oil fatty acids (IfishFA), AC16:0, AC16:1c9, AC18:0, AC18:1t, AC18:1c, AC18:2, AC18:3, and total absorbed unsaturated fatty acids (TAunsatFA). In all final equations, we included the lowest number of significant $(P<0.05)$ variables that could account for the variation in the observed data. For each final regression, residuals were plotted against regression predictions to confirm that residuals were normally distributed. Because the $R^{2}$ statistic is inappropriate to describe regressions forced through the origin (Becker and Kennedy, 1992), this statistic is only used to describe regressions not forced through the origin. All statistical analyses were performed with STATA software (Stata, 2007).

\section{RESULTS AND DISCUSSION}

Although the studies used in this analysis were recent, there was an unfortunate lack of dietary information in some. Consequently, dietary data were estimated for some studies using nutrient information contained in CPM-Dairy. These estimates will have lowered the strength of association of estimates made by regression. Further, some papers did not provide sufficient detail on fatty acid composition to meet the detail required in this study, which necessitated a number of assumptions as described in the companion paper (Moate et al., 2007). As discussed in the companion paper, these assumptions may result in some slight overestimation of the contribution of some of the C18:1, C18:2, and C18:3 fatty acid isomers. Despite these limitations in data quality, the study provides considerable insight to relationships between the physiological state of cows and diets fed with milk fatty acid production. The data set used was based on a large number and broad range of diets, including TMR and pasture-based diets and many with supplemental fat sources. These 


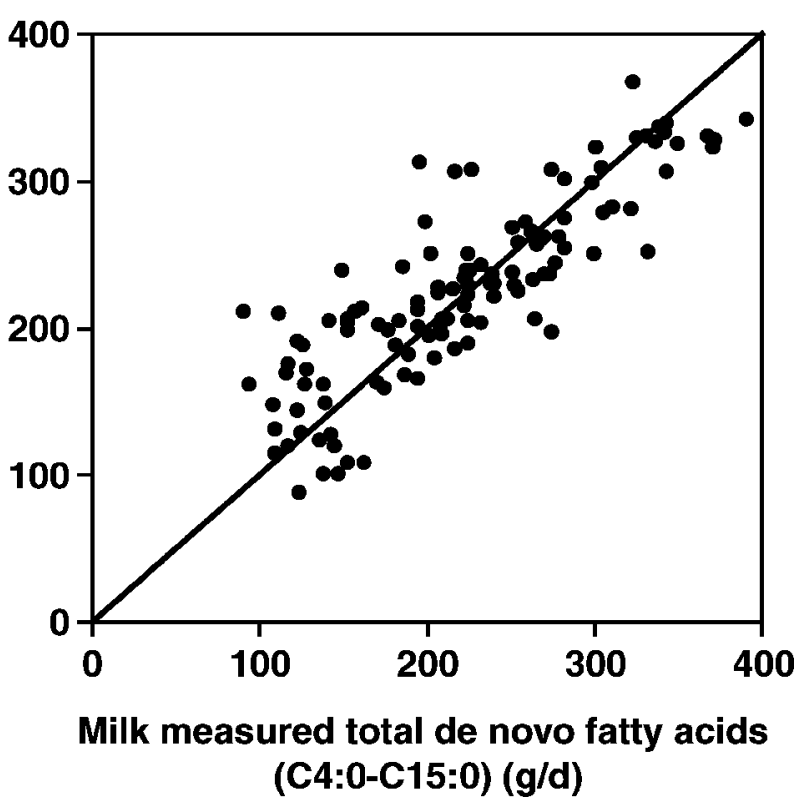

Figure 1. Comparison of measured and predicted production ( $\mathrm{g} /$ d) of total de novo fatty acids (C4:0 to C15:0). The solid line is the line of identity.

factors suggest that the findings are likely to be relevant to many feeding and management circumstances.

\section{Production of De Novo Fatty Acids}

Regression equation 1, which is shown in Table 1, predicts the PTdenovo in milk. The regression had an $\mathrm{R}^{2}$ of 0.76 and a root mean square error of $37.4 \mathrm{~g} / \mathrm{d}$. Equation 1 included a constant and 6 explanatory variables: IFCHO, ATunsat, ATunsat ${ }^{2}$, Ifishfa, $\sqrt{D I M}$, and

Diet. It quantifies the effects that these factors have on the production of total de novo fatty acids. The positive influence of IFCHO is to be expected because milk de novo fatty acids are synthesized chiefly by chain elongation using acetate, which is the main product of rumen fermentation (Grummer, 1991). Further, BHBA, which is produced in the rumen epithelium from absorbed butyrate, provides about half of the first 4 carbons (primer) of de novo synthesized fatty acids (Bauman and Griinari, 2003). The negative curvilinear effect of unsaturated fatty acids on de novo fatty acids found in this analysis supports the findings of Banks et al. (1983). Further, this equation quantifies this effect by indicating that the greatest negative influence on the production of de novo fatty acid occurs when the estimated intestinal absorption of unsaturated fatty acids is about $276 \mathrm{~g} / \mathrm{d}$. The negative influence of feeding fish oil on the production of de novo fatty acids has been shown previously (Loor et al., 2005). The association $(P<0.05)$ between $\sqrt{D I M}$ and de novo milk fat produc-

tion is expected because stage of lactation has been well documented as influencing milk fat concentration (Palmquist et al., 1993). In this analysis, although we examined a variety of stage of lactation effects including a linear effect, a quadratic effect, and a square-root effect, $\sqrt{D I M}$ was the most significant.

Figure 1 shows the relationship between the predicted PTdenovo and the measured PTdenovo. Equations 2 to 9 (Table 2), which are the result of univariate regressions forced through the origin, and Figure 2 show relationships between total production of de novo fatty acids and production of individual de novo fatty acids. In all cases there were strongly positive linear relationships, and the coefficients of equations 2 to 9 sum approximately to unity. Equations 2 to 9 indicate that factors that influence total production of de novo fatty acids also influence production of individual de novo fatty acids in a similar manner. These closely interconnected relationships between the individual de novo fatty acids do not appear to have been previously highlighted in this way. When individual short-chain fatty acids are expressed as grams of FA per kilogram of milk rather than as proportions of total milk fat, then variation is much diminished (Syrstad et al., 1982). Chilliard et al. (2003), when reviewing physiological and nutritional factors affecting the fatty acid composition of goat milk, reported that milk fatty acids appeared to belong to 3 groups: the $\mathrm{C} 4$ to $\mathrm{C} 8$ group, the C10 to C16 group, and the C18 group. Chilliard et al. (2003) reported that the C4 to C8 group was not highly correlated to the other 2 groups and that the $\mathrm{C} 10$ to C16 group was negatively correlated to the C18 fatty acid group. The graphs in Figure 2 provide strong evidence that in dairy cows the production of FA from $\mathrm{C} 4$ to $\mathrm{C} 15$ is strongly interrelated.

\section{Production of Palmitic and Palmitoleic Fatty Acids}

In Table 2 , equations 10 and 11 predict the production of palmitic (C16:0) and palmitoleic (cis-9 C16:1) acids respectively. The C16:0 in milk fat is believed to partly originate from C16:0 absorbed from the diet and also to be synthesized de novo in the mammary gland from acetate (Palmquist et al., 1967; Taylor and MacGibbon, 2002). Hermansen (1995) analyzed data pooled from 30 different experiments using regression methods and showed that the $\mathrm{C} 16: 0$ content of milk fat was positively related $(P<0.001)$ to the $\mathrm{C} 16: 0$ proportion of dietary fatty acids and negatively related $(P<0.001)$ to the total fatty acid concentration in the diet. Equation 10 
Table 2. Prediction of production (g/d) of C16:0, C16:1, total preformed fatty acids (>C16; PTpreform) and C17 fatty acids

\begin{tabular}{|c|c|c|c|c|c|c|}
\hline $\begin{array}{l}\text { Equation } \\
\text { no. }\end{array}$ & $\begin{array}{l}\text { Dependent } \\
\text { variable }\end{array}$ & 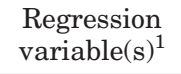 & Coefficient $\pm \mathrm{SE}$ & $\mathrm{t}$ & $\mathrm{N}(\mathrm{n})^{2}$ & $\mathrm{R}^{2}$ \\
\hline \multirow[t]{7}{*}{10} & \multirow[t]{7}{*}{ PC16:0 } & Intercept & $235.04 \pm 66.9$ & 3.51 & \multirow[t]{7}{*}{$120(29)$} & \multirow[t]{7}{*}{0.72} \\
\hline & & IFCHO & $24.0 \pm 5.96$ & 4.03 & & \\
\hline & & A16:0 & $0.416 \pm 0.083$ & 5.00 & & \\
\hline & & ATunsatFA & $-1.65 \pm 0.30$ & -5.48 & & \\
\hline & & ATunsatFA $^{2}$ & $0.0028 \pm 0.00069$ & 4.12 & & \\
\hline & & IfishFA & $-0.343 \pm 0.027$ & -12.5 & & \\
\hline & & $\sqrt{D I M}$ & $-4.76 \pm 2.27$ & -2.10 & & \\
\hline \multirow[t]{7}{*}{11} & \multirow[t]{7}{*}{ PC16:1c9 } & Intercept & $10.10 \pm 4.84$ & 2.09 & \multirow[t]{7}{*}{$109(27)$} & \multirow[t]{7}{*}{0.63} \\
\hline & & IFCHO & $1.55 \pm 0.55$ & 2.79 & & \\
\hline & & A16:0 & $0.025 \pm 0.0062$ & 4.07 & & \\
\hline & & ATunsatFA & $-0.069 \pm 0.017$ & 4.95 & & \\
\hline & & ATunsatFA $^{2}$ & $0.0001 \pm 0.00004$ & 2.84 & & \\
\hline & & $\sqrt{D I M}$ & $-0.544 \pm 0.197$ & 2.76 & & \\
\hline & & Diet & $2.46 \pm 1.21$ & 2.09 & & \\
\hline \multirow[t]{8}{*}{12} & \multirow{8}{*}{ PTpreform } & Intercept & $-300.5 \pm 106.8$ & -2.8 & \multirow[t]{8}{*}{$120(29)$} & \multirow[t]{8}{*}{0.75} \\
\hline & & ATotprefFA & $0.28 \pm 0.028$ & 10.1 & & \\
\hline & & DMI & $9.77 \pm 2.36$ & 4.14 & & \\
\hline & & DIM & $-0.65 \pm 0.16$ & -4.05 & & \\
\hline & & BW & $0.75 \pm 0.19$ & 3.89 & & \\
\hline & & IFishFA & $-0.162 \pm 0.037$ & -4.4 & & \\
\hline & & $\mathrm{MgO} 1$ & $0.1 \pm 25.9$ & 0.0 & & \\
\hline & & $\mathrm{MgO} 2$ & $-63.4 \pm 23.7$ & -2.68 & & \\
\hline \multirow[t]{6}{*}{$13 \mathrm{a}$} & \multirow[t]{6}{*}{ PC17 } & Intercept & $18.01 \pm 0.98$ & 18.31 & \multirow[t]{6}{*}{$78(19)$} & \multirow[t]{6}{*}{0.89} \\
\hline & & ATunsatFA & $-0.00225 \pm 0.0011$ & 2.02 & & \\
\hline & & $\sqrt{D I M}$ & $-0.60 \pm 0.074$ & 8.09 & & \\
\hline & & $\mathrm{MgO} 1$ & $3.59 \pm 0.92$ & 3.90 & & \\
\hline & & $\mathrm{MgO} 2$ & $2.55 \pm 0.66$ & 3.85 & & \\
\hline & & Diet & $-7.79 \pm 0.96$ & 8.14 & & \\
\hline \multirow[t]{2}{*}{$13 b$} & \multirow[t]{2}{*}{ PC17 } & Intercept & $2.95 \pm 2.74$ & 1.07 & \multirow[t]{2}{*}{78 (19) } & \multirow[t]{2}{*}{0.05} \\
\hline & & PTpreform & $0.011 \pm 0.006$ & 1.90 & & \\
\hline \multirow[t]{2}{*}{$13 \mathrm{c}$} & \multirow[t]{2}{*}{ PC17 } & Intercept & $-0.78 \pm 2.46$ & -0.32 & \multirow[t]{2}{*}{78 (19) } & \multirow[t]{2}{*}{0.37} \\
\hline & & PTotdenovo & $0.033 \pm 0.013$ & 2.50 & & \\
\hline
\end{tabular}

\footnotetext{
${ }^{1} \mathrm{~A} 16: 0=$ amount of $\mathrm{C} 16: 0$ absorbed from the intestines $(\mathrm{g} / \mathrm{d})$; ATotprefFA $=$ amount of total preformed fatty acids absorbed from the intestines $(\mathrm{g} / \mathrm{d})$; ATunsatFA = total amount of unsaturated fatty acids absorbed from the intestines $(\mathrm{g} / \mathrm{d})$; BW $=$ body weight $(\mathrm{kg})$; Diet $=$ a categorical variable, $0=$ pasture, $1=\mathrm{TMR}$; DMI = dry matter intake $(\mathrm{kg} / \mathrm{d})$; IFCHO = intake of fermentable carbohydrate $(\mathrm{kg} / \mathrm{d})$; IfishFA = intake of fish-oil fatty $\operatorname{acids}(\mathrm{g} / \mathrm{d}) ; \mathrm{MgO}=$ a categorical variable, $0=$ no magnesium supplement, 1 = magnesium supplement up to $0.2 \%$ of diet DMI, $2=$ magnesium supplement greater than $0.2 \%$ of DMI; PTotdenovo = total production of de novo fatty acids $(\mathrm{g} / \mathrm{d})$; PTpreform = total production of preformed fatty acids $(\mathrm{g} / \mathrm{d})$.

${ }^{2} \mathrm{~N}=$ total number of diets, $\mathrm{n}=$ total number of experiments.
}

extends the findings of Hermansen (1995) by showing as one might expect that the actual yield of $\mathrm{C} 16: 0$ in milk is positively linearly related $(P<0.001)$ to the amount of $\mathrm{C} 16: 0$ absorbed from the intestines. The regression coefficient $( \pm \mathrm{SE})$ associated with $\mathrm{C} 16: 0$ was $0.401 \pm 0.080$, which suggests that for every $1 \mathrm{~g}$ of C16:0 absorbed, $0.401 \mathrm{~g}$ was transferred to milk. This interpretation must be moderated by the observation that the regression equation also indicated that the production of C16:0 was negatively and quadratically $(P<0.001)$ associated with the total amount of unsaturated fatty acids absorbed in the intestines. Thus, transfer of absorbed dietary fatty acids to milk can be considered to be a competitive process. Equation 10 also indicates that the production of $\mathrm{C} 16: 0$ is strongly positively related $(P<0.001)$ to IFCHO. This supports the hypothesis that a substantial amount of C16:0 is produced de novo in the cow's mammary gland from the products of rumen fermentation (Taylor and MacGibbon, 2002).

It has long been known that intake of fish oil fatty acids can cause milk fat depression (Storry et al., 1974) and recently, fish oil has been shown to reduce the production of C16:0 (Lacasse et al., 2002; Loor et al., 2005). Equation 10 supports these findings and provides a quantification of this effect. We speculate that the relationship between $\sqrt{D I M}$ and production of $\mathrm{C} 16: 0$ may be influenced by many processes that change as lactation advances. These processes include reduced feed intake and increased mobilization of body fat in early lactation, maximum feed intake in midlactation, reduction in rumen volume and concomitantly reduced feed intake with advancing pregnancy, deposition of fat 

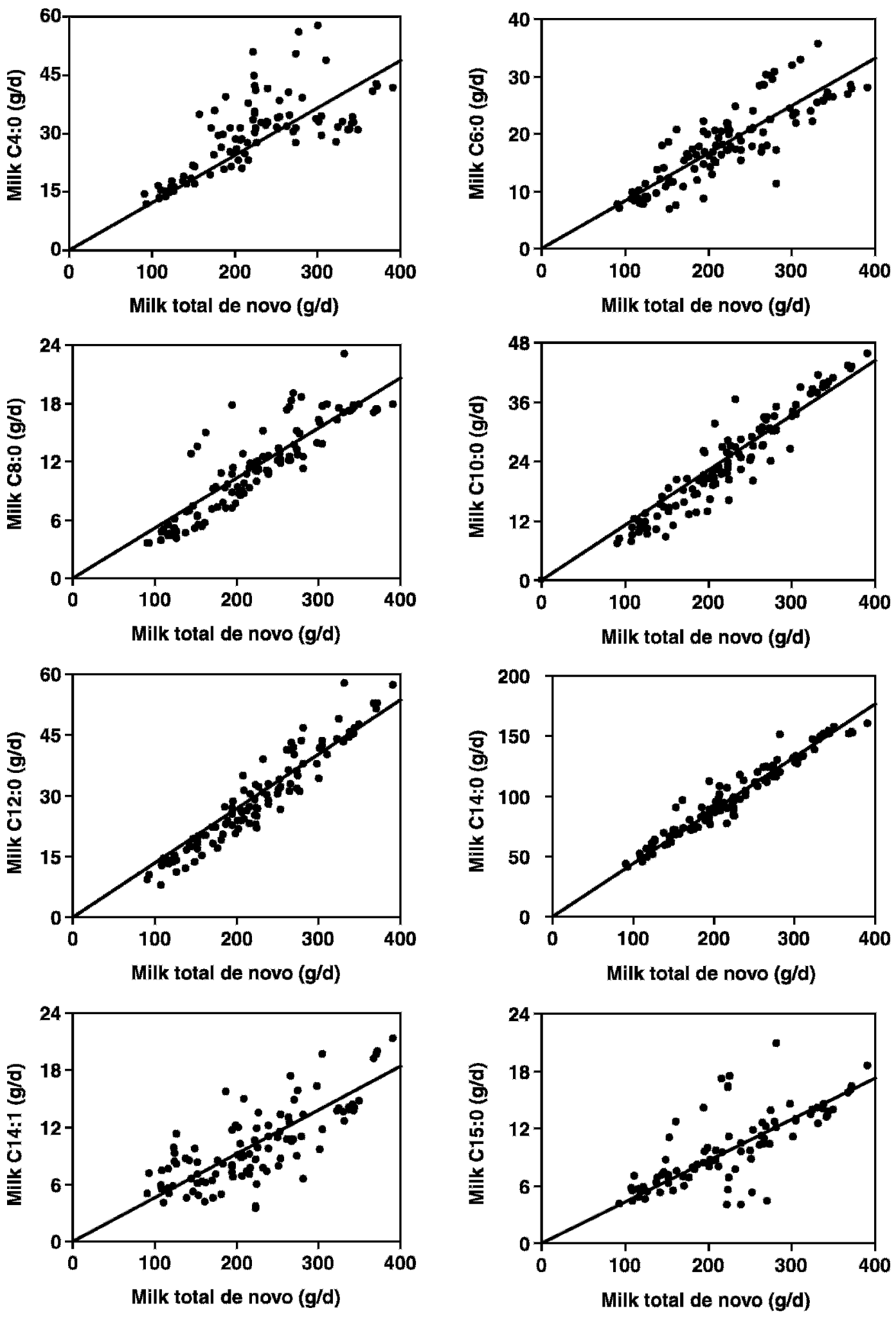

Figure 2. Prediction of production (g/d) of individual de novo fatty acids based on production of total de novo fatty acids (C4:0 to C15:0). In each panel, the solid line is the regression line forced through the origin. These regression lines correspond to equations 2 to 9 shown in Table 1. 


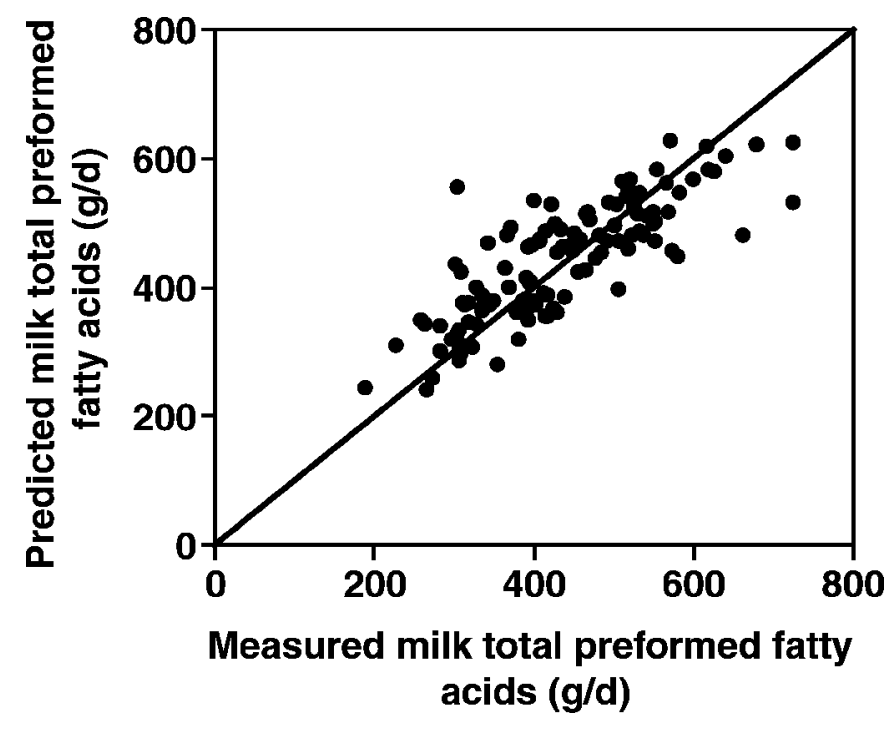

Figure 3. Comparison of measured and predicted production (g/ d) of total preformed fatty acids ( $>$ C16). The solid line is the line of identity.

in adipose tissue, and apoptosis of mammary cells in late lactation.

The cis-9 C16:1 is believed to be produced in the mammary gland by the desaturation of C16:0 (Bickerstaffe and Annison, 1970; Enoch et al., 1976). It is not surprising, therefore, that many of the factors that influence production of C16:0 have corresponding effects on the production of cis-9 C16:1. For example, IFCHO $(P<0.01)$ and the amount of $\mathrm{C} 16: 0$ absorbed from the intestines were positively related $(P<0.001)$ to production of cis-9 C16:1 (see equation 11). No significant relationship was found between the amount of C16:1 absorbed from the intestines and production of cis-9 C16:1 in milk. We suggest that the generally minor amount ( 1 to $5 \mathrm{~g} / \mathrm{d}$ ) of C16:1 absorbed from the intestines is insignificant with respect to the large quantities (usually $>70 \mathrm{~g} / \mathrm{d}$ ) of C16:0 absorbed from typical diets for cows (Moate et al., 2004). As with the production of C16:0, production of cis-9 C16:1 was negatively related $(P<0.01)$ to the total amount of unsaturated fatty acids absorbed in the intestines and negatively related $(P<$ $0.01)$ to $\sqrt{D I M}$. The categorical variable Diet in equation

11 indicates that approximately $2.4 \mathrm{~g} / \mathrm{d}$ more of $c i s-9$ C16:1 is produced on TMR-based diets compared with pasture-based diets.

\section{Production of Total Preformed Fatty Acids}

Equation 12 (Table 2), and Figure 3 show that approximately $75 \%$ of the variation in total production of preformed fatty acids could be explained with a regression equation containing the 6 variables DMI, DIM, ATotprefFA, BWT, IFishFA, and $\mathrm{MgO}$. Previous reviews identified the potential impact if not the magnitude of many of these factors on production of preformed fatty acids (Jensen et al., 1991; Palmquist et al., 1993). It is, therefore, not surprising that a strong positive relationship was found between the total amount of preformed fatty acids absorbed and the amount of preformed fatty acids produced in milk. Palmquist et al. (1993) found a quadratic relationship between intake of total C18 fatty acids and production of total C18 fatty acids in milk fat, but explained just $18 \%$ of the variation. The other 5 variables in equation 12 explain a substantial amount of the variation in production of total preformed fatty acids. The negative impact of the intake of fish oil fatty acids on milk fat production has been known for many years (Storry et al., 1974). The influence of DIM or stage of lactation on production of milk fatty acids has also been discussed by several reviewers (Grummer, 1991; Palmquist, et al., 1993; Chilliard et al., 2003). Mobilization of adipose reserves depends on energy balance and body condition of cows (Grummer, 1991; Palmquist, et al., 1993; Chilliard et al., 2003). Therefore, we speculate that the relationship between the production of preformed fatty acids and DIM may be more complex than the simple linear effect used in this regression, and further research in this area may be warranted.

The inclusion of BW in equation 12 is consistent with the hypothesis that part of the production of preformed fatty acids arises from the mobilization of adipose reserves (Palmquist, et al., 1993; Chilliard et al., 2003). The effect of dietary intake of buffers and $\mathrm{MgO}$ on production of total milk fat and on production of individual fatty acids has not been examined in recent reviews. Recent research (Kalscheur et al., 1997; Khorasani and Kennelly, 2001; Thivierge et al., 2001) supported earlier research (Thomas and Emery, 1969) that found positive effects of buffers and $\mathrm{MgO}$ supplementation in reducing milk fat depression when cows are fed high-concentrate, low-fiber diets.

The negative effect of high levels $(>0.2 \%$ on a DM basis) of dietary $\mathrm{MgO}$ on production of total preformed fatty acids is surprising because DMI was positively related $(P<0.01)$ to intake of magnesium (data not shown). Further, in other experiments that used diets with low NDF, significant effects of buffer/MgO on preformed milk fatty acids were not observed (Kalscheur et al., 1997; Kennelly et al., 1999). In subsequent equations, it is shown that dietary $\mathrm{MgO}$ has different effects on production of specific preformed fatty acids. Further research to elucidate how buffers and $\mathrm{MgO}$ influence the production of classes of fatty acids or individual fatty acids is warranted. 


\section{Production of C17 Fatty Acids}

Equation 13a in Table 2 contains the set of variables that best describe the production of $\mathrm{C} 17$ fatty acids. An interesting aspect to equation $13 \mathrm{a}$ is that the categorical variable Diet had a significant effect on the production of C17. This indicates that TMR diets are associated with lower levels of production of $\mathrm{C} 17$ fatty acids than those based on pasture. This prediction is consistent with a study that showed a positive linear increase in concentrations of $\mathrm{C} 17$ fatty acids in milk fat as the proportion of grass in the diet increased from zero to $100 \%$ (Couvreur et al., 2006).

The C17 fatty acids are generally considered to be a component of the preformed group of fatty acids. The regression variables present in equation $13 \mathrm{a}$ are, therefore, somewhat surprising because they do not closely mirror the regression variables used in equation 12 to describe production of total preformed fatty acids. In contrast to equation 12 , in equation 13 a, high levels of $\mathrm{MgO}$ have a positive impact on production of $\mathrm{C} 17$ fatty acids. Equation 13b shows that there is a weak linear relationship between the production of $\mathrm{C} 17$ and preformed fatty acids, whereas equation $13 \mathrm{c}$ shows that there is a stronger relationship between the production of $\mathrm{C} 17$ and the production of total de novo fatty acids. Thus, by considering equations $13 \mathrm{a}, 13 \mathrm{~b}$, and $13 \mathrm{c}$, it appears that the origins of $\mathrm{C} 17$ fatty acids in milk fat may, like those of C16:0, be partly intermediate between being synthesized de novo in the mammary gland and being preformed. However, equations $13 \mathrm{a}, 13 \mathrm{~b}$, and $13 \mathrm{c}$ are also consistent with the theory that $\mathrm{C} 17$ milk fatty acids may originate in part from rumen microbes (Dewhurst et al., 2000).

\section{Production of Stearic Acid}

Of the many variables and combinations of variables that were examined, just 4 variables, DMI, A18:0, $\mathrm{MgO}$, and Ifishfa, were found to consistently describe the production of stearic acid (C18:0; see Table 3, equation 14a). It is perhaps not surprising that DMI was one of these variables because DMI is generally linearly related to milk production. Similarly, it is not surprising that production of stearic acid was related to the amount of absorbed stearic acid (Hermansen, 1995). Equation 14a is consistent with the findings of Lacasse et al. (2002) and Loor et al. (2005) in that it indicates that production of C18:0 declines with the intake of fish oil fatty acids. Reports on the influence of supplemental $\mathrm{MgO}$ on production of individual milk fatty acids are not common. The finding in equation $14 \mathrm{a}$ of a strong $(P<0.01)$ negative impact of high levels of supplemental $\mathrm{MgO}$ on the production of $\mathrm{C} 18: 0$ is intriguing; $\mathrm{MgO}$ was not associated with a positive effect on the production of either trans-11, C18:1 or cis-9, C18:1. This suggests that $\mathrm{MgO}$ supplements neither inhibit $\mathrm{BH}$ of C18:1 fatty acids nor enhance activity of the $\Delta^{9}$-desaturase enzyme within the mammary gland. It is possible that the observed inhibitory effect of high levels of dietary $\mathrm{MgO}$ on the production of stearic acid may be caused by another phenomenon such as inhibition of the intestinal absorption of stearic acid. This possibility warrants further research. Equation 14b shows that the production of stearic acid constitutes a relatively constant $23 \%$ of the total preformed fatty acids.

\section{Production of Oleic Acid}

As shown by equation 15a (Table 3), and as would be expected from the work of Hermansen (1995), the production of oleic acid (cis-9 C18:1) is directly related to the amount of cis-9 C18:1 absorbed. It is known that cis-9 C18:1 is also produced in the mammary gland by the desaturation of stearic acid (Kinsella, 1972), and equation 15a quantifies this effect. Equation 15a also supports the findings of Lacasse et al. (2002) and Loor et al. (2005), because it predicts a strong negative effect from intake of fish oil fatty acids on the production of oleic acid. Equation 15b shows that cis-9 C18:1 is the most abundant preformed fatty acid and that its production constitutes a relatively constant $43 \%$ of the production of total preformed fatty acids.

\section{Production of Total and Individual Isomers of Trans Octadecenoic Acid}

Sixty-nine percent of the variation in the production of total trans octadecenoic acid (PC18:1tTot) was described by an equation with 5 factors (Table 3, equation 16a). As expected, equation $16 \mathrm{a}$ predicts that PC18:1tTot is strongly positively related to the amount of C18:1t absorbed in the intestines. Equation 16a also predicts that there is a positive quadratic relationship between intake of fish oil fatty acids and PC18:1tTot, with maximum PC18:1tTot occurring when there is an intake of approximately $350 \mathrm{~g} / \mathrm{d}$ of fish oil fatty acids. The positive quadratic relationship between DIM and PC18:1tTot predicts that the peak in the production of PC18:1tTot occurs at approximately 138 DIM. The coefficients for the categorical variable $\mathrm{MgO}$ indicate that when there is a small amount (greater than zero, but less than $0.2 \%$ on DM basis) of supplemental $\mathrm{MgO}$ in the diet, then PC18:1tTot will be enhanced. The Diet variable indicates that pasture-based diets are associated with greater levels of PC18:1tTot, a finding consistent with the substantially greater concentration of total trans-C18:1 found in milk fat when the pasture proportion of the diet increased from zero to $100 \%$ 
Table 3. Prediction of production (g/d) of stearic acid (PC18:0) and C18 monounsaturated fatty acids

\begin{tabular}{|c|c|c|c|c|c|c|}
\hline $\begin{array}{l}\text { Equation } \\
\text { no. }\end{array}$ & $\begin{array}{c}\text { Dependent } \\
\text { variable }\end{array}$ & $\begin{array}{l}\text { Regression } \\
\text { variable }(\mathrm{s})^{1}\end{array}$ & Coefficient $\pm \mathrm{SE}$ & $\mathrm{t}$ & $\mathrm{N}(\mathrm{n})^{2}$ & $\mathrm{R}^{2}$ \\
\hline \multirow[t]{6}{*}{$14 \mathrm{a}$} & \multirow[t]{6}{*}{ PC18:0 } & Intercept & $43.9 \pm 18.66$ & 2.35 & \multirow[t]{6}{*}{$120(29)$} & \multirow[t]{6}{*}{0.58} \\
\hline & & DMI & $2.25 \pm 1.00$ & 2.23 & & \\
\hline & & A18:0 & $0.095 \pm 0.030$ & 3.21 & & \\
\hline & & $\mathrm{MgO} 1$ & $-6.48 \pm 13.79$ & -0.47 & & \\
\hline & & $\mathrm{MgO} 2$ & $-43.75 \pm 14.14$ & 3.09 & & \\
\hline & & IfishFA & $-0.125 \pm 0.020$ & -6.20 & & \\
\hline $14 \mathrm{~b}$ & PC18:0 & PTpreform & $0.23 \pm 0.011$ & 21.0 & $120(29)$ & $\mathrm{NA}^{3}$ \\
\hline \multirow[t]{4}{*}{$15 \mathrm{a}$} & \multirow[t]{4}{*}{ PC18:1c9 } & Intercept & $125.8 \pm 16.1$ & 7.83 & \multirow[t]{4}{*}{$120(29)$} & \multirow[t]{4}{*}{0.56} \\
\hline & & $\mathrm{A} 18: 1 \mathrm{c} 9$ & $0.475 \pm 0.114$ & 4.17 & & \\
\hline & & A18:0 & $0.149 \pm 0.050$ & 2.95 & & \\
\hline & & IfishFA & $-0.235 \pm 0.020$ & -11.44 & & \\
\hline $15 b$ & PC18:1c9 & PTpreform & $0.43 \pm 0.017$ & 25.9 & $120(29)$ & NA \\
\hline \multirow[t]{9}{*}{$16 \mathrm{a}$} & \multirow[t]{9}{*}{ PC18:1tTot } & Intercept & $8.37 \pm 6.29$ & 1.33 & \multirow[t]{9}{*}{$94(23)$} & \multirow[t]{9}{*}{0.69} \\
\hline & & A18:1t & $0.161 \pm 0.047$ & 3.42 & & \\
\hline & & IfishFA & $0.167 \pm 0.023$ & 7.35 & & \\
\hline & & IfishFA $^{2}$ & $-2.4 \mathrm{E}-4 \pm 3.7 \mathrm{E}-5$ & -6.40 & & \\
\hline & & DIM & $0.457 \pm 0.107$ & 4.29 & & \\
\hline & & $\mathrm{DIM}^{2}$ & $-1.7 \mathrm{E}-3 \pm 3.7 \mathrm{E}-4$ & 4.51 & & \\
\hline & & MgO1 & $14.19 \pm 4.30$ & 3.30 & & \\
\hline & & $\mathrm{MgO} 2$ & $-6.52 \pm 5.102$ & -1.28 & & \\
\hline & & Diet & $-18.444 \pm 2.40$ & -7.72 & & \\
\hline $16 \mathrm{~b}$ & PC18:1tTot & PTpreform & $0.076 \pm 0.007$ & 10.76 & $90(22)$ & NA \\
\hline 17 & PC18:1t6-8 & PC18:1tTotal & $0.121 \pm 0.023$ & 5.17 & $21(6)$ & NA \\
\hline 18 & PC18:1t9 & PC18:1tTotal & $0.102 \pm 0.023$ & 5.43 & $21(6)$ & NA \\
\hline 19 & PC18:1t10 & PC18:1tTotal ${ }^{2}$ & $0.0072 \pm 0.014$ & 5.12 & $21(6)$ & NA \\
\hline 20 & PC18:1t11 & PC18:1tTotal & $0.411 \pm 0.627$ & 6.55 & $21(6)$ & NA \\
\hline 21 & PC18:1t12 & PC18:1tTotal & $0.169 \pm 0.023$ & 4.44 & $15(4)$ & NA \\
\hline
\end{tabular}

${ }^{1} \mathrm{~A} 18: 0$ = amount of C18:0 absorbed from the intestines (g/d); A18:1c9 = amount of C18:1c9 absorbed from the intestines (g/d); A18:1t = amount of C18:1t (all isomers) absorbed from the intestines ( $\mathrm{g} / \mathrm{d}$ ); Diet = a categorical variable, 0 = pasture, 1 = TMR; IfishFA = Intake of fish-oil fatty acids ( $\mathrm{g} / \mathrm{d}) ; \mathrm{MgO}=$ a categorical variable, $0=$ no magnesium supplement, $1=$ magnesium supplement up to $0.2 \%$ of diet DMI, $2=$ magnesium supplement greater than $0.2 \%$ of DMI; PC18:1tTotal = total production of all isomers of C18:1t $(\mathrm{g} / \mathrm{d})$; PTpreform $=$ total production of preformed fatty acids $(\mathrm{g} / \mathrm{d})$.

${ }^{2} \mathrm{~N}=$ total number of diets, $\mathrm{n}=$ total number of experiments.

${ }^{3} \mathrm{NA}=$ not appropriate.

(Couvreur et al., 2006). Equation 16b indicates that PC18:1tTot constitutes approximately $8 \%$ of the production of total preformed fatty acids.

The production of specific trans octadecenoic isomers in milk is of great interest because of possible associations between dietary intake of trans fatty acids and cardiovascular disease (Mozaffarian et al., 2006). Equations $17,18,19,20$, and 21 describe the production of individual isomers of trans-C18:1 in terms of PC18:1tTotal.

\section{Production of Linoleic and Conjugated Linoleic Acid}

Table 4 presents equations that predict the production of polyunsaturated fatty acids in milk. As shown by equation $22 \mathrm{a}$, and as would be expected from the work of Hermansen (1995), the production of linoleic acid (cis-9, cis-12 C18:2) is directly related to the amount of C18:2 absorbed. Despite an extensive examination of many other dietary and cow factors, only 2 other variables, DMI and IfishFA, were found to influ- ence the production of $c i s-9$, cis-12 C18:2. This is surprising because Hermansen (1995) reported a negative relationship between the proportion of $\mathrm{C} 16: 0$ in dietary fatty acids and the proportion of C18:2 and C18:3 in milk fatty acids. Equation $22 \mathrm{~b}$ shows that the production of $c i s-9$, cis-12 C18:2 constitutes a relatively constant $7.0 \%$ of the production of total preformed fatty acids.

Conjugated linoleic acids (CLA) are a family of isomers of linoleic acid characterized by 2 carbon-to-carbon double bonds that are separated by a single carbonto-carbon bond. Specific isomers of CLA, especially cis9, trans-11 C18:2, are of interest because these have human health benefits. The trans-10, cis-12 C18:2 isomer has potent effects on lowering milk fat concentration when injected or infused postruminally (Baumgard et al., 2000).

Equation 23a (Table 4), which contains 4 variables, explains $71 \%$ of the variation in the PC18:2 c9t11. The involvement of A18:1t in equation 23a is consistent with the main source of production of cis-9, trans-11 C18:2 in the mammary gland being from the action of $\Delta^{9}$ - 
Table 4. Prediction of the production (g/d) of polyunsaturated fatty acids in milk

\begin{tabular}{|c|c|c|c|c|c|c|}
\hline $\begin{array}{l}\text { Equation } \\
\text { no. }\end{array}$ & $\begin{array}{l}\text { Dependent } \\
\text { variable }\end{array}$ & $\begin{array}{c}\text { Regression } \\
\text { variable }(s)^{1}\end{array}$ & Coefficient $\pm \mathrm{SE}$ & $\mathrm{t}$ & $\mathrm{N}(\mathrm{n})^{2}$ & $\mathrm{R}^{2}$ \\
\hline \multirow[t]{4}{*}{$22 \mathrm{a}$} & \multirow[t]{4}{*}{ PC18:2c9,c12 } & Intercept & $-35.7 \pm 16.3$ & -2.19 & \multirow[t]{4}{*}{$120(29)$} & \multirow[t]{4}{*}{0.70} \\
\hline & & A18:2 & $0.38 \pm 0.05$ & 7.85 & & \\
\hline & & DMI & $2.37 \pm 0.83$ & 2.76 & & \\
\hline & & IfishFA & $-0.023 \pm 0.010$ & -2.23 & & \\
\hline $22 \mathrm{~b}$ & PC18:2c9,c12 & PTpreform & $0.070 \pm 0.007$ & 9.74 & $120(29)$ & $\mathrm{NA}^{3}$ \\
\hline \multirow[t]{8}{*}{$23 \mathrm{a}$} & \multirow[t]{8}{*}{ PC18:2c9,t11 } & Intercept & $3.29 \pm 0.44$ & 7.49 & \multirow[t]{8}{*}{$76(19)$} & \multirow[t]{8}{*}{0.71} \\
\hline & & A18:1t & $0.045 \pm 0.0085$ & 5.21 & & \\
\hline & & IfishFA & $0.046 \pm 0.009$ & 5.38 & & \\
\hline & & IfishFA $^{2}$ & $-6.2 \mathrm{E}-5 \pm 1.8 \mathrm{E}-5$ & -3.44 & & \\
\hline & & Buffer1 & $3.38 \pm 1.55$ & 2.18 & & \\
\hline & & Buffer2 & $4.18 \pm 0.89$ & 4.72 & & \\
\hline & & $\mathrm{MgO} 1$ & $-2.40 \pm 1.15$ & 2.09 & & \\
\hline & & $\mathrm{MgO} 2$ & $-4.19 \pm 0.65$ & 6.45 & & \\
\hline $23 \mathrm{~b}$ & PC18:2c9,t11 & PTpreform & $0.018 \pm 0.002$ & 7.24 & $76(19)$ & NA \\
\hline \multirow[t]{3}{*}{24} & \multirow[t]{3}{*}{ PC18:2t10,c12 } & Intercept & $0.0044 \pm 0.100$ & 0.04 & \multirow[t]{3}{*}{$35(9)$} & \multirow[t]{3}{*}{0.42} \\
\hline & & A18:2 & $0.0084 \pm 0.0026$ & 3.22 & & \\
\hline & & Buffer1 & $-0.39 \pm 0.090$ & 4.22 & & \\
\hline \multirow[t]{7}{*}{$25 \mathrm{a}$} & \multirow[t]{7}{*}{ PC18:3 } & Intercept & $0.62 \pm 2.03$ & 0.30 & \multirow[t]{7}{*}{$114(28)$} & \multirow[t]{7}{*}{0.50} \\
\hline & & A18:3 & $0.310 \pm 0.044$ & 7.06 & & \\
\hline & & $\mathrm{A} 18: 3^{2}$ & $-1.5 \mathrm{E}-3 \pm 2.4 \mathrm{E}-4$ & 6.13 & & \\
\hline & & DIM & $-8.9 \mathrm{E}-3 \pm 4.2 \mathrm{E}-3$ & -2.12 & & \\
\hline & & DMI & $0.247 \pm 0.083$ & 2.96 & & \\
\hline & & IfishFA & $-0.0045 \pm 0.0015$ & -2.97 & & \\
\hline & & A18:1t & $-0.022 \pm 0.0057$ & -3.88 & & \\
\hline $25 \mathrm{~b}$ & PC18:3 & PTpreform & $0.012 \pm 0.0012$ & 9.53 & $114(28)$ & NA \\
\hline \multirow[t]{5}{*}{26} & \multirow[t]{5}{*}{ PC20:0 } & Intercept & $6.06 \pm 0.93$ & 6.50 & \multirow[t]{5}{*}{$30(8)$} & \multirow[t]{5}{*}{0.82} \\
\hline & & A18:3 & $0.0039 \pm 0.00053$ & 7.32 & & \\
\hline & & BW & $-0.014 \pm 0.0015$ & -9.35 & & \\
\hline & & DIM & $-0.0022 \pm 0.0007$ & -2.96 & & \\
\hline & & DMI & $0.199 \pm 0.030$ & 6.57 & & \\
\hline \multirow[t]{4}{*}{27} & \multirow[t]{4}{*}{ PC20:5 } & Intercept & $-0.41 \pm 0.33$ & 1.24 & \multirow[t]{4}{*}{$39(10)$} & \multirow[t]{4}{*}{0.84} \\
\hline & & IfishFA & $0.0042 \pm 0.00023$ & 18.71 & & \\
\hline & & DIM & $-0.0050 \pm 0.0009$ & -5.81 & & \\
\hline & & DMI & $0.051 \pm 0.013$ & 3.98 & & \\
\hline \multirow[t]{3}{*}{28} & \multirow[t]{3}{*}{ PC22:6 } & Intercept & $0.067 \pm 0.067$ & 1.01 & $31(8)$ & 0.59 \\
\hline & & IfishFA & $0.0023 \pm 0.0003$ & 7.29 & & \\
\hline & & AC18:3 & $0.0195 \pm 0.0076$ & 2.59 & & \\
\hline 29 & POther & IFCHO & $4.78 \pm 1.88$ & 2.55 & $120(29)$ & NA \\
\hline & & AOther & $0.58 \pm 0.27$ & 2.16 & & \\
\hline
\end{tabular}

\footnotetext{
${ }^{1} \mathrm{~A} 18: 1 \mathrm{t}=$ amount of $\mathrm{C} 18: 1 \mathrm{t}$ (all isomers) absorbed from the intestines ( $\mathrm{g} / \mathrm{d}$ ); A18:2 = amount of C18:2
} absorbed from the intestines (g/d); A18:3 = amount of C18:3 absorbed from the intestines ( $\mathrm{g} / \mathrm{d})$; buffer = categorical variable, $0=$ no buffer, $1=$ buffer up to $0.2 \%$ of DMI, $2=$ buffer more than $2 \%$ of DMI; BW = body weight $(\mathrm{kg}) ; \mathrm{DMI}=$ dry matter intake $(\mathrm{kg} / \mathrm{d}) ; \mathrm{IfishFA}=$ intake of fish-oil fatty acids $(\mathrm{g} / \mathrm{d}) ; \mathrm{MgO}=\mathrm{a}$ categorical variable, $0=$ no magnesium supplement, $1=$ magnesium supplement up to $0.2 \%$ of diet DMI, 2 = magnesium supplement greater than $0.2 \%$ of DMI; PC18:1tTotal $=$ total production of all isomers of $\mathrm{C} 18: 1 \mathrm{t}(\mathrm{g} / \mathrm{d})$; PTpreform = total production of preformed fatty acids $(\mathrm{g} / \mathrm{d})$; IFCHO = intake of fermentable carbohydrate $(\mathrm{kg} / \mathrm{d})$.

${ }^{2} \mathrm{~N}=$ total number of diets, $\mathrm{n}=$ total number of experiments.

${ }^{3} \mathrm{NA}=$ not appropriate.

desaturase on trans-11 C18:1 (trans-vaccenic acid, TVA; Mosley et al., 2006). The positive linear effect of intake of fish oil fatty acids on PC18:2c9t11 may reflect an inhibition of complete ruminal $\mathrm{BH}$ of $\mathrm{C} 18$ fatty acids. Consequently, TVA would accumulate within the rumen, in turn increasing subsequent systemic production of cis-9, trans-11 C18:2 (Wasowska, et al., 2006). The negative quadratic effect of high concentrations of fish oil on production of $c i s-9$, trans-11 C18:2 may reflect production of large amounts of TVA that exceed the desaturation capacity of the $\Delta^{9}$-desaturase enzyme within the mammary gland, or that high levels of specific fatty acids from fish oil may inhibit the $\Delta^{9}$-desaturase activity of the mammary gland (Dhiman et al., 2005).

The significant positive effect of high levels of buffer and negative influence of $\mathrm{MgO}$ on PC18:2c9t11 are intriguing. We have been unable to identify experiments that report the separate effects of different levels of supplemental dietary buffer and $\mathrm{MgO}$ on CLA concentrations in milk. In a review of factors influencing CLA content of milk, Dhiman et al. (2005) stated that "Re- 
duction in ruminal $\mathrm{pH}$ decreases the population of cellulolytic bacteria and other microbes responsible for lipid $\mathrm{BH}$ and the production of CLA and TVA." On this basis, one might expect both additional dietary buffer and $\mathrm{MgO}$ would lead to increased production of CLA. On the other hand, if low ruminal $\mathrm{pH}$ selectively inhibited the $\mathrm{BH}$ of trans-C18:1 fatty acids, desaturation within the mammary gland of absorbed trans-11 C18:1 would lead to high levels of CLA. In support of this latter possibility, there have been 2 studies in which addition of buffer to high-concentrate diets reduced production of trans C18:1 fatty acids in milk (Kalscheur et al., 1997; Kennelly et al., 1999). Because both additional dietary buffer and $\mathrm{MgO}$ were not significantly related to production of either cis-9 C16:1 or cis-9 C18:1, we can conclude that these factors did not influence the activity of the $\Delta^{9}$-desaturase enzyme within the mammary gland. The effects of buffer and $\mathrm{MgO}$ on production of CLA must be viewed with caution because these are based on different levels of buffer and $\mathrm{MgO}$ across experiments. Such data are subject to the influence of unmeasured or unknown variables that may confound results. Therefore, we suggest that these findings warrant further research. Equation $23 \mathrm{~b}$ (Table 4), indicates that PC18:2 c9t11 constitutes just $1.8 \%$ of the total production of preformed fatty acids.

Despite much research into trans-10, cis-12 C18:2, the factors that influence its production are not well understood. Equation 24 (Table 4), indicates that PC18:2 t10c12 is positively related to AC18:2 and negatively related to the inclusion of buffer in the diet. The majority of A18:2 is likely to be cis-9, cis-12 C18:2 (Loor et al., 2005). We interpret the involvement of A18:2 in equation 24 to indicate that the dietary situations that are conducive to large amounts of cis-9, cis-12 C18:2 escaping the rumen are also conducive to trans-10, cis12 C18:2 being produced in the rumen by isomerization of cis-9, cis-12 C18:2. Inclusion of buffer, principally sodium bicarbonate, in diets has long been known to reduce the depression in milk fat percentage associated with restricted roughage high-concentrate diets (Thomas and Emery, 1969). This analysis suggests that a potential mechanism by which bicarbonate achieves this effect is by reduced formation of trans-10, cis-12 C18:2 within the rumen.

\section{Production of Linolenic Acid}

Linolenic acid (cis-9, cis-12, cis-15 C18:3) is an $\mathrm{n}$ 3 fatty acid that has been ascribed numerous health benefits (Givens et al., 2000). Equation 25a (Table 4) indicates that production of cis-9, cis-12, cis-15 C18:3 is positively quadratically related to A18:3. The positive influence of DMI and the negative influence of DIM,
IfishFA, and A18:1t on PC18:3c9,c12,c15 are not unexpected for the same reasons that these variables influence the production of the other fatty acids discussed above. Equation 25b (Table 4) indicates that PC18:3 constitutes just $1.2 \%$ of the total production of preformed fatty acids.

\section{Production of Arachidic, Eicosapentaenoic, and Docosahexaenoic Acids}

There are few data available in studies or reviews that focus on arachidic acid (C20:0). We have previously shown that C20:0 is generally present in milk fat at about $1.5 \mathrm{mg} / \mathrm{g}$ or in milk at about $0.05 \mathrm{~g} / \mathrm{L}$ (Moate et al., 2007). Although C20:0 is believed to be formed systemically by the action of elongase enzymes on C16:0 and C18:0 (Leonard et al., 2004), there were no significant relationships between the amounts of C16:0 or C18:0 absorbed from the intestines and the daily milk production of C20:0. Equation 26 (Table 4) indicates that production of $\mathrm{C} 20: 0$ in milk fat is positively related to DMI and, surprisingly, to the amount of C18:3 absorbed from the intestines. Equation 26 also indicates that production of C20:0 was negatively related to DIM and BW.

Eicosapentaenoic acid (cis-5, cis-8, cis-11, cis-14, cis$17 \mathrm{C} 20: 5)$ and docosahexaenoic acid (cis-4, cis-7, cis-10, cis-13, cis-16, cis-19 C22:6) are $2 \mathrm{n}-3$ fatty acids that are required for many metabolic processes in humans and animals and which have beneficial health effects (Givens et al., 2000; Pawlosky, 2005). The concentrations (mg/g of total fatty acids) of C20:5 (1.0 \pm 0.6$)$ and C22:6 (0.7 \pm 0.7$)$ are generally very low compared with concentrations of many other fatty acids (Moate et al., 2007). Although there are only very small concentrations of C20:5 and C22:6 in land plants, there are high concentrations in marine organisms (algae, fish, shrimp, marine mammals; Givens et al., 2000). Currently, there is some controversy as to the extent of $\mathrm{BH}$ in the rumen of these fish oils (Dohme et al., 2003; AbuGhazaleh and Jenkins, 2004). Despite this controversy, equations 27 and 28 (Table 4 ) indicate that the production of C20:5 and C22:6 in milk is strongly $(P<$ 0.01 ) positively related to the intake of fish oil fatty acids. It is known that in humans, C20:5 and C22:6 can be synthesized within the liver from the precursor C18:3 (Pawlosky, 2005). We did not find any relationship between the production in milk of C20:5 and intestinal absorption of C18:3. However, equation 28 is consistent with the findings of Pawlosky (2005) in that it predicts that the production of $\mathrm{C} 22: 6$ is positively related $(P<0.05)$ to the amount of $\mathrm{C} 18: 3$ absorbed from the diet. 


\section{Production of Other Fatty Acids}

Besides the specific fatty acids already discussed, there are very many other fatty acids that can be detected in milk fat. In many reports, these fatty acids are grouped under the catch-all term "other" or "unknown" fatty acids. This group of other fatty acids is by no means a definitive term because, depending on each particular experiment, it may or may not include oddand branched-chain fatty acids, unidentified isomers of C18 unsaturated fatty acids, a host of unusual fatty acids that are normally present in milk fat at very low concentrations, and any artifact of chemical analysis. Thus, the prediction of the production of other fatty acids will necessarily present difficulties. Equation 29 (which is forced through the origin) predicts the production of other fatty acids based on IFCHO and the amount of other fatty acids absorbed from the intestines. The involvement of fermentable carbohydrate in equation 29 suggests that some of the "other" milk fatty acids may well be short-chain or medium-chain fatty acids that are produced de novo in the mammary gland by chain extension from acetate. It is also plausible that some absorbed "other" fatty acids would be transferred to the mammary gland.

\section{Mammary Transfer Coefficients of Fatty Acids}

Despite the importance of absorbed LCFA to milk fat production, there has been a dearth of research aimed at determining the direct transfer coefficients of specific absorbed dietary LCFA to their corresponding LCFA in milk fat. In this analysis, the estimates for the coefficients for the direct transfer of the major absorbed LCFA to corresponding milk fatty acids were C16:0: 42\% (equation 10); C18:0: 9.5\% (equation 14a); cis-9 C18:1: 47.5\% (equation 15a); all isomers of trans-C18:1: 16.1\% (equation 16a), cis-9, cis-12 C18:2: 38\% (equation 22a); and cis-9, cis-12, cis-15 C18:3: 31\% (equation 25a). The particularly low transfer coefficient for C18:0 probably arose because much of the C18:0 that is transferred from the blood to the mammary gland is, as is suggested by equation $15 \mathrm{a}$, desaturated in the mammary gland to produce cis-9 C18:1. Combining coefficients from equations $14 \mathrm{a}$ and $15 \mathrm{a}$, we can estimate that approximately $24.4 \%$ of absorbed stearic acid was transferred to the mammary gland and approximately $61 \%$ of this was desaturated to cis-9 C18:1. Similarly, taking into account that considerable trans-11 C18:1 is known to be desaturated in the mammary gland to cis-9, trans$11 \mathrm{C} 18: 2$, and using coefficients from equations $16 \mathrm{a}$ and $23 \mathrm{a}$, we can estimate that approximately $21 \%$ of absorbed total trans C18:1 was transferred to the mammary gland, and approximately $21 \%$ of this was desaturated to cis-9, trans-11 C18:2. This estimate of the transfer coefficient for trans-C18:1 is somewhat less than the estimate of $33 \%$ obtained by Mosley et al. (2006), who used a stable isotope tracer. However, our estimate of approximately $21 \%$ desaturation of total trans C18:1 is similar to the estimate of $25.7 \%$ found by Mosley et al. (2006). The above estimated transfer coefficients for the major LCFA should not be thought of as fixed coefficients, but, as indicated by equations 10 to 29 , the transfer of each specific absorbed fatty acid to milk fat may be modulated by a large set of dietary and animal factors.

\section{CONCLUSIONS}

This analysis examined effects of a range of cow and dietary factors on production of individual fatty acids in bovine milk. Our analysis provided equations that predict production of 26 major fatty acids in milk fat. Up to 6 factors were used to describe production of specific fatty acids. The $\mathrm{R}^{2}$ for each equation was generally above 0.5 , indicating that each equation could account for more than $50 \%$ of the variation in the data. This work has opened the possibility that these empirical equations, or equations like them, may be used in computer programs such as CPM-Dairy to predict daily productions of major individual fatty acids and total milk fatty acids and concentrations of these. Further data are required to validate these equations. In developing the equations, data from the majority of published experiments that reported essential appropriate data were used. Unfortunately, few independent data remain to validate the equations. Many studies on milk fatty acids have been published without sufficient details on cattle or dietary treatment to allow further evaluation. In particular, many otherwise excellent articles report in detail the fatty acid concentration and fatty acid profile of fat supplements, but they report the total ether extract or crude fat content of the basal diet, but fail to report the total fatty acid concentration or fatty acid profile of the basal diet. Although $16 \mathrm{yr}$ have passed since Grummer (1991) lamented that "Dose response curves for changes in milk fatty acid profiles due to increasing levels of supplemental fat are not abundant," and despite publication of many hundreds of articles on milk fatty acids, there is still a dearth of publications that include necessary data for model development and validation. The future of dairy research will be greatly expedited if experiments are reported that provide the type of cow and dietary details and milk fatty acid profiles described in this article.

\section{REFERENCES}

AbuGhazaleh, A. A., and T. C. Jenkins. 2004. Disappearance of docosahexaenoic and eicosapentaenoic acids from cultures of mixed ruminal microorganisms. J. Dairy Sci. 87:645-651. 
Banks, W., J. L. Clapperton, and W. Steele. 1983. Dietary manipulation of the content and fatty acid composition of milk fat. Proc. Nutr. Soc. 42:399-406.

Bauman, D. E., and J. M. Griinari. 2003. Nutritional regulation of milk fat synthesis. Annu. Rev. Nutr. 23:203-227.

Baumgard, L. H., B. A. Corl, D. A. Dwyer, A. Saebo, and D. E. Bauman. 2000. Identification of the conjugated linoleic acid isomer that inhibits milk fat synthesis. Am. J. Physiol. Regul. Integr. Comp. Physiol. 278:R179-R184.

Becker, B., and P. Kennedy. 1992. A lesson in least squares and R squared. Am. Stat. 46:282-283.

Bickerstaffe, R., and E. F. Annison. 1970. The desaturase activity of goat and sow mammary tissue. Comp. Biochem. Phys. 35:653665 .

Boston, R. C., Z. Dou, and W. Chalupa. 2002. Models in nutritional management. Pages 2378-2389 in Encyclopedia of Dairy Science. Vol. 4. H. Roginski, J. W. Fuquay, and P. F. Fox, ed. Elsevier Science Ltd., London, UK.

Chilliard, Y., A. Ferlay, J. Rouel, and G. Lambert. 2003. A review of nutritional and physiological factors affecting goat milk lipid synthesis and lipolysis. J. Dairy Sci. 86:1751-1770.

Couvreur, S., C. Hurtaud, C. Lopez, L. DeLaby, and J. L. Peyraud. 2006. The linear relationship between the proportion of fresh grass in the cow diet, milk fatty acid composition, and butter properties. J. Dairy Sci. 89:1956-1969.

Dewhurst, R. J., D. R. Davies, and R. J. Merry. 2000. Microbial protein supply from the rumen. Anim. Feed Sci. Technol. 85:1-21.

Dhiman, T. R., S. H. Nam, and A. L. Ure. 2005. Factors affecting conjugated linoleic acid content in milk and meat. Crit. Rev. Food Sci. Nutr. 45:463-482.

Dohme, F., V. Fievez, K. Raes, and D. I. Demeyer. 2003. Increasing levels of two different fish oils lower ruminal biohydrogenation of eicosapentaenoic and docosahexaenoic acid in vitro. Anim. Res. $52: 309-320$

Enoch, H. G., A. Catala, and P. Strittmatter. 1976. Mechanism of rat liver microsomal stearoyl-CoA desaturase. J. Biol. Chem. 251:5095-5103.

Givens, D. I., B. R. Cottrill, M. Davies, P. A. Lee, R. J. Mansbridge, and A. R. Moss. 2000. Sources of n-3 polyunsaturated fatty acids additional to fish oil for livestock diets-A review. Nutr. Abstr. Rev. 70:4-59.

Grummer, R. R. 1991. Effect of feed on the composition of milk fat. J. Dairy Sci. 74:3244-3257.

Hanigan, M., and R. Baldwin. 1994. A mechanistic model of mammary gland metabolism in the lactating cow. Agric. Syst. 45:369-419.

Hermansen, J. E. 1995. Prediction of milk fatty acid profile in dairy cows fed dietary fat differing in fatty acid composition. J. Dairy Sci. 78:872-879.

Jensen, R. G., A. M. Ferris, and C. J. Lammi-Keefe. 1991. The composition of milk fat. J. Dairy Sci. 74:3228-3243.

Kalscheur, K. F., B. B. Teter, L. S. Piperova, and R. A. Erdman. 1997. Effect of dietary forage concentration and buffer addition on duodenal flow of trans-C18:1 fatty acids and milk fat production in dairy cows. J. Dairy Sci. 80:2104-2114.

Kennelly, J. J., B. Robinson, and G. R. Khorasani. 1999. Influence of carbohydrate source and buffer on rumen fermentation characteristics, milk yield and milk composition in early lactation Holstein cows. J. Dairy Sci. 82:2486-2496.

Khorasani, G. R., and J. J. Kennelly. 2001. Influence of carbohydrate source and buffer on rumen fermentation characteristics, milk yield, and milk composition in late-lactation Holstein cows. J. Dairy Sci. 84:1707-1716.

Kinsella, J. 1972. Stearyl CoA as a precursor of oleic acid and glycerolipids in mammary microsomes from lactating bovine: Possible regulatory steps in milk triglyceride synthesis. Lipids 7:349-355.

Lacasse, P., J. J. Kennelley, L. Delbecchi, and C. E. Ahnadi. 2002. Addition of protected and unprotected fish oil to diets for dairy cows. I. Effects on yield, composition and taste of milk. J. Dairy Res. 69:511-520.

Leonard, A. E., S. L. Pereira, H. Sprecher, and Y. S. Huang. 2004 Elongation of long-chain fatty acids. Prog. Lipid Res. 43:36-54.

Loor, J. J., M. Doreau, J. M. Chardigny, A. Ollier, J. L. Sebedio, and Y. Chilliard. 2005. Effects of ruminal or duodenal supply of fish oil on milk fat secretion and profiles of trans-fatty acids and conjugated linoleic acid isomers in dairy cows fed maize silage. Anim. Feed Sci. Technol. 119:227-246.

McGuire, M. A., and D. E. Bauman. 2002. Milk biosynthesis and secretion. Pages 1826-1834 in Encyclopedia of Dairy Science. Vol. 3. H. Roginski, J. Fuquay, and P. Fox, ed. Elsevier Science Ltd., London, UK.

Moate, P. J., R. C. Boston, I. J. Lean, and W. Chalupa. 2006. Short Communication: Further validation of the fat sub-model in the Cornell-Penn-Miner Dairy model. J. Dairy Sci. 89:1052-1056.

Moate, P. J., W. Chalupa, R. C. Boston, and I. J. Lean. 2007. Milk fatty acids I: Variation in the concentration of individual fatty acids in bovine milk. J. Dairy Sci. 90:4730-4739.

Moate, P. J., W. Chalupa, T. C. Jenkins, and R. C. Boston. 2004. A model to describe ruminal metabolism and intestinal absorption of LCFA in dairy cows. Anim. Feed Sci. Technol. 112:79-105.

Mosley, E. E., B. Shafii Dagger, P. J. Moate, and M. A. McGuire. 2006. Cis-9, trans-11 conjugated linoleic acid is synthesized directly from vaccenic acid in lactating dairy cattle. J. Nutr. 136:570-575.

Mozaffarian, D., M. B. Katan, A. Ascherio, M. J. Stampfer, and W. C. Willett. 2006. Trans fatty acids and cardiovascular disease. N. Engl. J. Med. 345:1601-1613.

Palmquist, D. L., A. D. Beaulieu, and D. M. Barbano. 1993. Feed and animal factors influencing milk fat composition. J. Dairy Sci. 76:1753-1771.

Palmquist, D. L., C. L. Davis, R. E. Brown, and D. Sachan. 1967. Availability and metabolism of various substrates in ruminants. Entry rate into the body and incorporation into milk fat of $\mathrm{D}(-)$ $\beta$-hydroxybutyrate. J. Dairy Sci. 52:633-638.

Parodi, P. W. 2002. Conjugated linoleic acid. Pages 1587-1594 in Encyclopedia of Dairy Sciences. H. Roginski, J. W. Fuquay, and P. F. Fox, ed. Elsevier Science Ltd., London, UK.

Pawlosky, R. J. 2005. Chapter 4, Modeling alpha-linolenic and linoleic acid in human adults and infants. Pages 59-74 in Mathematical Modeling in Nutrition and Toxicology. J. L. Hargrove and C. D. Berdanier, ed. Mathematical Biology Press, Athens, GA.

Shorten, P. R., T. B. Pleasants, and G. Upreti. 2004. A mathematical model for mammary fatty acid synthesis and triglyceride assembly: The role of stearoyl CoA desaturase (SCD). J. Dairy Res. 71:385-397.

Stata. 2007. Stata Statistical Software. Release 9.0 ed. Stata Corporation, College Station, TX

Storry, J. E., P. E. Brumby, A. J. Hall, and B. Tuckley. 1974. Effects of free and protected forms of cod liver oil on milk fat secretion in the dairy cow. J. Dairy Sci. 57:1046-1049.

Syrstad, O., N. Standal, and Ø. Karijord. 1982. Concentration of various fatty acids in milk. Z. Tierzucht. Zuchtungsbiol. 99:94-99.

Taylor, M. W., and A. K. H. MacGibbon. 2002. Fatty acids. Pages 1550-1554 in Encyclopedia of Dairy Science. Vol. 3. H. Roginski, J. Fuquay, and P. Fox, ed. Elsevier Science Ltd., London, UK.

Thivierge, M. C., P. Y. Chouinard, J. Levesque, V. Girard, J. R. Seoane, and G. J. Brisson. 2001. Effects of buffers on milk fatty acids and mammary arterio-venous differences in dairy cows fed Ca salts of fatty acids. J. Dairy Sci. 81:2001-2010.

Thomas, J. W., and R. S. Emery. 1969. Additive nature of sodium bicarbonate and magnesium oxide on milk fat concentrations of milking cows fed restricted-roughage rations. J. Dairy Sci. 52:1762-1769.

Wasowska, I., M. R. G. Maia, K. M. Niedzwiedzka, M. Czauderna, and J. M. Ribeiro. 2006. Influence of fish oil on ruminal biohydrogenation of C18 unsaturatated fatty acids. Br. J. Nutr. 95:1199-1211. 